\title{
DA NATUREZA JURÍDICA DO PEDÁGIO
}

\section{TOLL - THE LEGAL NATURE}

\author{
1João Glicério de Oliveira Filho \\ ${ }^{2}$ Gustavo Teixeira Moris
}

\section{RESUMO}

O presente trabalho tem por escopo investigar a natureza jurídica do pedágio. Investiga-se o papel do pedágio no direito positivo brasileiro, sua finalidade, seu regime jurídico e seus critérios definidores. Por zelo metodológico, busca-se apresentar conceitos embasados de taxa, preço público, serviço público e tarifa. Realiza-se, em seguida, uma investigação histórica do pedágio no direito estrangeiro e brasileiro, para que se possa compreender o funcionamento do instituto no atual sistema constitucional. Por fim, conclui-se que o pedágio, ainda que realizado por meio de concessão, possui natureza jurídica de taxa, sujeito a todos os requisitos e garantias desta espécie tributária.

Palavra Chave: Pedágio. Tributo. Taxa. Preço Público. Tarifa. Constituição. Limitações ao poder de tributar. Natureza jurídica.

\begin{abstract}
:
The purpose of this work is to investigate the legal nature of tolls. It investigates the role of the toll in Brazilian positive law, its purpose, its legal regime and its defining criteria. Due to methodological zeal, we seek to present concepts based on rate, public price, public service and tariff. Then, a historical investigation of the toll in foreign and Brazilian law is carried out, so that one can understand the functioning of the institute in the current constitutional system. Finally, it can be concluded that tolls, even if made through a concession, have legal nature of tax, subject to all the requirements and guarantees of this tax rate.
\end{abstract}

Keyword: Toll. Tribute. Rate. Public Price. Rate. Constitution. Limitations on the power to tax. Legal nature

\footnotetext{
${ }^{1}$ Possui Mestrado e Doutorado em Direito pela Universidade Federal da Bahia, UFBA - BA, (Brasil) . Professor de Direito Empresarial daUniversidade Federal da Bahia, UFBA - BA, (Brasil). É advogado. Email:joao@joaoglicerio.com

${ }^{2}$ Professor de Direito Tributário, Especialista em Direito Tributário pela Pontifícia Universidade Católica,PUC/SP - SP, (Brasil).É advogado. E-mail: gtmoris@gmail.com.
} 


\section{INTRODUÇÃO}

O pedágio constitui espécie tributária especificamente prevista na Constituição Federal. A Carta Magna, contudo, limitou-se a mencionar incidentalmente o instituto, tratando-o como uma ressalva à impossibilidade dos entes federados estipularem tributos que limitem o tráfego de pessoas ou bens, conforme consubstanciado no artigo 150, inciso V, da Lei Maior.

De fato, o texto constitucional não cuida de conceituar ou mesmo estipular um arcabouço regulatório mínimo para o pedágio. Fica a encargo da legislação ordinária, da jurisprudência e da doutrina, por consequência, a tarefa de classificar e descrever o instituto. Contribuir para o esforço doutrinário de delinear as características jurídicas desta espécie tributária é justamente o intuito deste artigo.

Para tanto, ocuparem-nos no presente trabalho de analisar as principais características das taxas de serviço, quando este é efetivamente utilizado pelo contribuinte. Impõe-se, assim, um recorte específico na matéria, a qual, além de farta, é particularmente controversa.

O objetivo deste estudo é apontar os principais elementos que distinguem as taxas dos preços públicos e das tarifas. Busca-se, com este esforço, identificar o conceito, a classificação e a natureza jurídica do pedágio, concluindo que este é também uma espécie de taxa cobrada pela efetiva utilização de serviço público.

Para atingir o objetivo proposto, faz-se necessária prévia conceituação dos institutos tributários de "taxa", "preço público" e "tarifa", bem como da noção jurídica de "serviço público". Cumpre, ainda, analisar as relações travadas nas concessões de serviços públicos entre poder concedente, concessionária e usuário do serviço. No mais, será traçado também um breve esboço histórico do pedágio, no direito estrangeiro e brasileiro.

\section{O GÊNERO "TAXA"}

A taxa possui duas causas jurídicas, o que a distingue das demais espécies tributárias. Configuram fatos geradores de taxa o exercício regular do poder de polícia e a utilização, efetiva ou potencial, de serviços públicos específicos e divisíveis ${ }^{3}$. Deriva da soberania financeira do Estado, independentemente de qualquer elemento volitivo por parte do contribuinte ou de qualquer outra condição - a menos que expressamente estipulada em $l \mathrm{ei}^{4}$.

\footnotetext{
${ }^{3}$ MORAES, Bernardo Ribeiro de. Doutrina e Prática das Taxas. 2 ed. São Paulo: Quartier Latin. 2a edição. 2007. P. 32.

${ }^{4}$ Idem, p. 41.
} 
Nas palavras de Ramon Valdes Costa, "as taxas, como todos os tributos, são sempre obrigatórias, em virtude da decisão unilateral do Estado", que define seu critério material, critério espacial, sujeito ativo, sujeito passivo, base da cálculo e alíquota ou ainda cobrada com valor fixo ${ }^{5}$. Podem ser instituídas e cobradas pela autoridade estatal sempre que houver um serviço público de sua titularidade ${ }^{6}$, específico e individualizável em relação ao contribuinte ${ }^{7}$.

Importante ressaltar que o contribuinte poderá, a depender do caso, utilizar ou não o serviço público do qual resulta a taxa. Não ocorrendo a utilização, inexiste o fato gerador da obrigação tributária e, como conseqüência, não haverá a cobrança de qualquer valor. Optando o contribuinte por utilizar o serviço, será sujeito passivo da obrigação tributária na forma em que tiver sido estabelecida em $1 \mathrm{ei}^{8}$.

\subsection{OS PREÇOS PÚBLICOS}

Diferentemente da taxa, o preço público demanda a manifestação de vontade do particular para a estipulação do quantum a ser pago. Em outras palavras, não nasce unilateramente da lei, mas do comum acordo firmado entre as partes. Diferencia-se da taxa também por admitir, como sujeito passivo de eventual obrigação, não apenas o particular, mas também a autoridade estatal.

Preços públicos são normalmente verificados na realização de obras públicas, compras públicas, contratação de empresas privadas para a prestação de serviços gerais e nas alienações onerosas feitas pelo poder público ao particular. É configurado, ainda, em outras circunstâncias que dependam de um ajuste entre administração e administrado para o surgimento de um preço.

Na obra pública, a administração contrata particular para a sua execução, mediante ajuste realizado através de processo licitatório, geralmente adjudicando o objeto à empresa que

\footnotetext{
${ }^{5}$ COSTA, Ramon Valdes. Curso de Derecho Tributário. 1 ed. v. 1. Montevidedo: Impressora Uruguaya Colombino: 1970. P. 313.

${ }^{6}$ Lembremos que podem haver serviços prestados por particulares, mas tal particularidade não retira do Estado a titularidade do serviço. Nesses casos a prestação do serviço é que é concedida a terceiros, permanecendo o Estado com a titularidade do serviço.

7 Nesse particular não devemos confundir a compulsoriedade da exação com a compulsoriedade da utilização do serviço. São coisas distintas. A compulsoriedade do tributo é atributo que pertine a sua criação, independe de manifestação de vontade do contribuinte para que exista a hipótese de incidência. A necessidade de manifestação de vontade por sua vez existirá smpre, na formação de contratos, na utilização ou não do serviço, seja ele publico ou privado. Achar que a compulsoriedade na utilização do serviço é que caracteriza a taxa é confundir as coisas.

${ }^{8}$ Importante ressaltar que neste trabalho estamos analisando a taxa pela efetiva utilização de serviço publico especifico e divisível. Dessa maneira, a taxa oriunda de serviços públicos postos à disposição não será abordada no presente estudo.
} 
oferecer o menor preço ${ }^{9}$ - o mesmo ocorrendo na contratação de empresa para prestação de serviços gerais. Nas alienações onerosas feitas pelo poder público ao particular, por outro lado, os objetos são adjudicados ao particular que oferecer o maior preço para a obtenção dos bens.

Em todos os casos mencionados acima, a manifestação de vontade na formação do contrato é imprescindível para a existência da obrigação. Em última análise, não pode existir preço público sem expressa volição do particular, visto que possui natureza contratual e não compulsória. Pode-se definir o preço público, portanto, como todo valor fixado por um acordo de vontade entre no mínimo duas partes, em que uma delas seja o Poder Público ${ }^{10}$.

\section{SERVIÇOS PÚBLICOS}

O Ministro Moreira Alves, no X Simpósio de Direito Tributário, lançando sistemático olhar sobre os serviços procurou identificar três espécies de serviços públicos. A primeira delas seria formada pelos serviços propriamente estatais, prestados em decorrência da soberania do Estado e remunerados mediante o estabelecimento de taxa. Esta categoria abrangeria os serviços judiciários.

Outra categoria seria a dos serviços essenciais ao interesse público, cuja prestação estaria relacionada a um benefício criado para a coletividade. Ocorreria nos casos de fornecimento de água e coleta de lixo. A sua remuneração ocorreria também por meio da taxa, tendo em vista o vínculo existente entre o serviço e o interesse supra-individual.

Por fim, verifica-se ainda a existência de serviços públicos não essenciais, cuja fruição ficaria a critério do usuário. Esses serviços poderiam ser delegados e seriam remunerados por preço público. Exemplos clássicos desta espécie de serviços são os de telefonia e de energia elétrica.

A par da brilhante sistematização ter jogado forte luz sobre o tema, a sistematização incorre em problema de ordem prática, por distinguir serviços de fornecimento de água e serviço de energia elétrica, ambos essenciais ao mundo atual e ambos passíveis de delegação. Verifica-se ainda uma incongruência jurídica nesta classificação, que elege a compulsoriedade

\footnotetext{
9 Vale Lembrar que a Lei 8.666/93 estabelece outros tipos de licitação tal como técnica e preço e melhor técnica.

${ }^{10}$ Assim têm-se como exemplo de preços públicos: Os preços fixados para construção de uma obra onde o contratante é o Poder Público e o contratado é um particular, os preços fixados em um contrato de locação, onde o locador é o Poder Público e o locatário é um particular, os preços fixados para a entrega de um dado bem, onde o comprador é o Poder Público e o vendedor é o particular entre outros exemplos que veremos adiante.
} 
da utilização do serviço como critério para caracterizá-lo. Nesse sentido nos leciona o professor Marçal Justen Filho ${ }^{11}$ :

O problema fundamental não reside na espontaneidade (ou não) do consumo do serviço, mas na sua submissão ao regime de direito público. Serviços públicos podem, respeitados os parâmetros constitucionais, ser objeto de disciplina legal impondo sua compulsoriedade. Mas isso não é inerente ao conceito de serviço público. Há serviços que não são compulsórios nem por isso deixam de ser públicos. Enfim, a compulsoriedade da fruição somente é admissível nas hipóteses de regime de direito público, mas não é da essência do conceito de serviço público.

O professor Geraldo Ataliba reconhecia que a Constituição Federal impõe a taxa como instrumento adequado a promover a remuneração de serviços públicos específicos e divisíveis prestados, apontando que sua delegação não importaria na alteração da natureza do seu regime jurídico $^{12}$. Juridicamente, poderíamos compreender os serviços públicos como todos os serviços de titularidade do Estado, cuja prestação é passível de concessões ou permissão, sempre através de licitação, conforme literalidade do artigo 175 da Carta Magna ${ }^{13}$.

Juridicamente, e de forma estática, pode-se afirmar que todos os serviços extraídos das competências e atribuições estabelecidas nos artigos 21 e 23 da Constituição Federal são, em tese públicos. Exemplos indiscutíveis são os serviços de emissão de moeda, telecomunicação e radiodifusão, correios, instalação de energia elétrica, organização e manutenção do Poder Judiciário, dentre outros ${ }^{14}$.

11 JUSTEN FILHO, Marçal. Teoria Geral das Concessões de Serviço Público. 1 ed. São Paulo: Dialética, 2003. P. 344.

12 ATALIBA. Geraldo. Hipótese de Incidência Tributária. 5 ed. São Paulo: Malheiros, 2011. P. 140 e ss.

13 “Art. 175. Incumbe ao Poder Público, na forma da lei, diretamente ou sob regime de concessão ou permissão, sempre através de licitação, a prestação de serviços públicos”.

14 Art. 21. Compete à União: III - assegurar a defesa nacional; IV - permitir, nos casos previstos em lei complementar, que forças estrangeiras transitem pelo território nacional ou nele permaneçam temporariamente; VII - emitir moeda; VIII - administrar as reservas cambiais do País e fiscalizar as operações de natureza financeira, especialmente as de crédito, câmbio e capitalização, bem como as de seguros e de previdência privada; X - manter o serviço postal e o correio aéreo nacional; XI - explorar, diretamente ou mediante autorização, concessão ou permissão, os serviços de telecomunicações, nos termos da lei, que disporá sobre a organização dos serviços, a criação de um órgão regulador e outros aspectos institucionais; XII - explorar, diretamente ou mediante autorização, concessão ou permissão: a) os serviços de radiodifusão sonora, e de sons e imagens; b) os serviços e instalações de energia elétrica e o aproveitamento energético dos cursos de água, em articulação com os Estados onde se situam os potenciais hidroenergéticos; c) a navegação aérea, aeroespacial e a infra-estrutura aeroportuária; d) os serviços de transporte ferroviário e aquaviário entre portos brasileiros e fronteiras nacionais, ou que transponham os limites de Estado ou Território; e) os serviços de transporte rodoviário interestadual e internacional de passageiros; f) os portos marítimos, fluviais e lacustres; XIII - organizar e manter o Poder Judiciário, o Ministério Público e a Defensoria Pública do Distrito Federal e dos Territórios; XIV - organizar e manter a polícia civil, a polícia militar e o corpo de bombeiros militar do Distrito Federal, bem como prestar assistência financeira ao Distrito Federal para a execução de serviços públicos, por meio de fundo próprio; XV - organizar e manter os serviços oficiais de estatística, geografia, geologia e cartografia de âmbito nacional;

Art. 23. É competência comum da União, dos Estados, do Distrito Federal e dos Municípios: 
Registre-se, por fim, que o serviço público concedido à iniciativa privada não tem a natureza ou o regime jurídico alterado. A mera concessão não transfere a titularidade do serviço, que continua a pertencer ao Estado. Apenas a execução dos serviços é efetivamente concedida.

A outorga da prestação do serviço público preserva o regime jurídico em sua totalidade, determinando que sua remuneração ocorra mediante o estabelecimento de taxa. Ratifica-se, portanto, que a compulsoriedade da utilização do serviço em nada se relaciona com a remuneração por meio de taxa. É a natureza pública do serviço - e não essência compulsória que determina o modelo de remuneração tributária.

\subsection{A TARIFA NOS SERVIÇOS PÚBLICOS CONCEDIDOS}

Em seu artigo150, VI, “a”, a Constituição Federal proíbe a instituição de impostos sobre o patrimônio, a renda ou serviços uns dos outros ${ }^{15}$. Segundo o professor Paulo de Barros Carvalho, a norma imunizante vincula o legislador ordinário na atribuição de competências tributárias dos entes federados. Dessa forma, do mesmo modo que a Constituição atribui a um ente a competência para instituição de determinado tributo, explicita determinadas hipóteses de não incidência ${ }^{16}$.

Em idêntico sentido, a norma constante do $\$ 3^{\circ}$ do mesmo dispositivo também conformaria o plexo de competência tributária dos referidos entes federados. Por consequências, não se estende a imunidade acima mencionada à adimplemento por serviços típicos de empreendimentos privados ou remunerados por meio de preços ou tarifas - aqueles que, embora prestados pelo Estado, não são serviços públicos em qualquer dos sentidos mais estritos.

I - zelar pela guarda da Constituição, das leis e das instituições democráticas e conservar o patrimônio público; II cuidar da saúde e assistência pública, da proteção e garantia das pessoas portadoras de deficiência; III - proteger os documentos, as obras e outros bens de valor histórico, artístico e cultural, os monumentos, as paisagens naturais notáveis e os sítios arqueológicos;IV - impedir a evasão, a destruição e a descaracterização de obras de arte e de outros bens de valor histórico, artístico ou cultural; V - proporcionar os meios de acesso à cultura, à educação e à ciência; VI - proteger o meio ambiente e combater a poluição em qualquer de suas formas; VII - preservar as florestas, a fauna e a flora; VIII - fomentar a produção agropecuária e organizar o abastecimento alimentar; IX - promover programas de construção de moradias e a melhoria das condições habitacionais e de saneamento básico; X - combater as causas da pobreza e os fatores de marginalização, promovendo a integração social dos setores desfavorecidos”.

15 "Art. 150. Sem prejuízo de outras garantias asseguradas ao contribuinte, é vedado à União, aos Estados, ao Distrito Federal e aos Municípios: VI - instituir impostos sobre: a) patrimônio, renda ou serviços, uns dos outros. $\int 3^{\circ}-$ As vedações do inciso VI, "a", e do parágrafo anterior não se aplicam ao patrimônio, à renda e aos serviços, relacionados com exploração de atividades econômicas regidas pelas normas aplicáveis a empreendimentos privados, ou em que haja contraprestação ou pagamento de preços ou tarifas pelo usuário, nem exonera o promitente comprador da obrigação de pagar imposto relativamente ao bem imóvel".

${ }^{16}$ CARVALHO. Paulo de Barros. Curso de Direito Tributário. São Paulo: Saraiva, 2003. P. 168-169. 
A primeira exceção ratifica a tese de que a natureza de um serviço não está necessariamente vinculada à pessoa do prestador. De fato, a imunidade busca abranger serviços essencialmente públicos, qualidade que não recai sobre serviços típicos do setor privados, ainda que prestados pelo Estado. Com efeito, o fato do Poder Público prestar determinados serviços não os transmuda de privados para públicos.

Na segunda exceção à imunidade dos entes federados, o serviço oferecido é público, prestado por terceiro, mediante concessão ou permissão, onde se exige tarifa do usuário do serviço público. Verifica-se que as hipóteses anti-imunizantes buscam atingir situações jurídicas distintas: a primeira relaciona-se à natureza do serviço prestado, enquanto a segunda está relacionada com a forma de remuneração ${ }^{17}$.

Os tomadores de ambos os serviços possuem natureza jurídica diferenciada, justamente pelos serviços serem diferenciados. O tomador do serviço privado é conhecido como “consumidor”, enquanto o tomador do serviço público é o usuário. Consumidor e usuário são categorias distintas, sujeitas a regimes jurídicos distintos. É o que se pode depreender do tratamento dado a cada uma das modalidades de serviços pelos artigos $170, \mathrm{~V}^{18}$, e 175 , parágrafo único, $\mathrm{II}^{19}$.

Com as premissas até aqui fixadas, torna-se possível afirmar que o serviço público efetivamente prestado ao usuário pode ser remunerado, conforme prevê a Constituição. Todavia, a exação cobrada pelo poder público ao usuário do serviço deverá ser uma taxa, a qual, caso fixada uniformemente e com base em valor fixo, ou ainda com base em valores padrões por faixa, deverá indicar uma tabela tarifada e será chamada de "tarifa".

Nessa linha, a tarifa só pode ser exigida do usuário do serviço público, visto que o consumidor está sujeito ao pagamento de preço. Sua fixação, evidentemente, deve seguir as regras para a fixação de taxa. Pode-se dizer, assim, que as tarifas são cobradas em decorrência da prestação de um serviço público concedido.

\footnotetext{
${ }^{17}$ Registre-se que, se o serviço público for prestado pelo Poder Público, a imunidade subsistirá, não sendo possível a instituição de impostos pelo serviço público prestado, nem no patrimônio afetado à tal prestação.

18 “Art. 170. A ordem econômica, fundada na valorização do trabalho humano e na livre iniciativa, tem por fim assegurar a todos existência digna, conforme os ditames da justiça social, observados os seguintes princípios: $V$ - defesa do consumidor.".

19 "Art. 175. Incumbe ao Poder Público, na forma da lei, diretamente ou sob regime de concessão ou permissão, sempre através de licitação, a prestação de serviços públicos. Parágrafo único. A lei disporá sobre: II - os direitos dos usuários (...). $\$ 3^{\circ}$ A lei disciplinará as formas de participação do usuário na administração pública direta e indireta, regulando especialmente: I - as reclamações relativas à prestação dos serviços públicos em geral, asseguradas a manutenção de serviços de atendimento ao usuário e a avaliação periódica, externa e interna, da qualidade dos serviços".
} 


\section{O PEDÁGIO: NOME DE UMA TARIFA PERTENCENTE AO GÊNERO TAXA}

O pedágio é o desdobramento de uma estratégia milenar de fazer fortuna. A cobrança pela passagem ou utilização de vias públicas ou privadas, terrestres ou fluviais, gravando o exercício da liberdade de circulação - direito irrenunciável do ser humano ${ }^{20}$-, foi desde cedo percebida como uma fonte inesgotável de recursos ${ }^{21}$.

Escritos antigos como a obra Arthasastra, elaborada na Índia por Kautilya (321. a.c), já registravam sua prática. Relata-se também a cobrança pela utilização de vias que ligavam a Síria à Babilônia, há mais de quatro mil $\operatorname{anos}^{22}$. A expansão do Império Romano levou a necessidade de construção de milhares de quilômetros de estradas, cujo financiamento era viabilizado pelos proprietários das terras por onde as estradas passavam ${ }^{23}$.

Na Idade Média, duques e marqueses detinham o comitatus, um conjunto das prerrogativas que seus antepassados tinham exercido em nome do rei, dentre as quais encontrava-se a cobrança, em proveito do conde, do pedágio ${ }^{24}$. Já no século XI, fortalecido o poder real, os pedágios eram executados por alcaides que mantinham poderes policiais sobre um território determinado. Nestes termos, os pedágios ampliaram-se significativamente a partir de $1050^{25}$.

A partir do Século XV o pedágio deixa progressivamente de ser cobrado sem contrapartida e passa a ter sua legalidade controlada pelo poder real, que fiscalizava os valores das tarifas em relação ao cumprimento do dever de manutenção da obra. Em 1464, Luis XI inicia a policie des péages e, com a criação dos correios e pelo édito de 1964, impõe-se a

\footnotetext{
20 Art. 150. Sem prejuízo de outras garantias asseguradas ao contribuinte, é vedado à União, aos Estados, ao Distrito Federal e aos Municípios:

$\mathrm{V}$ - estabelecer limitações ao tráfego de pessoas ou bens, por meio de tributos interestaduais ou intermunicipais, ressalvada a cobrança de pedágio pela utilização de vias conservadas pelo Poder Público;

21 SAVARIS, José Antônio. Pedágio: Conceitos e Trajetória Histórica. In: Caderno da Escola de Direito e Relações Internacionais, n. , p. 200-24, 2008.

${ }^{22}$ MACHADO, Kal. Concessões de Rodovias. Mito e realidade. São Paulo: Premio 2002. P. 79.

${ }^{23}$ È criado a figura do administrador de estradas que tinha atribuição de impor contribuições destinadas a construção e manutenção de novas estradas.

${ }^{24}$ FOURQUIN, Guy. Senhorio e Feudalidade na Idade Média.Lisboa. Lisboa: Edições 70, 1987. P. 47-48.

${ }^{25}$ A título ilustrativo verifique-se a declaração de um Castelão do século XI: "Reconheço ter prendido a mercadores de Langres que passavam pelo meu domínio. Arrebatei-lhes as mercadorias e guardei-as até o dia em o Bispo de Lagres e o abade de Cluni virem procurar-me para exigir reparações. Guardei para mim uma parte do que eu tomarae restitui o resto. Esses mercadores, a fim de obterem (a totalidade do que lhes tinha sido roubado) e de poderem para o futuro atravessar minhas terras sem inquietação, consentiram em pagar-me uma quantia certa a guisa de tributo... Resolvi então impor a todos os que atravessavam o meu território, por negócio ou peregrinação, um imposto chamado pedágio". Ibidem, p. 92.
} 
manutenção das vias da cidade por senhores e ordens religiosas que arrecadassem o pedágio em nome do rei $^{26}$.

Em 1724, por determinação do rei Luis XV uma comissão é criada com a função de pesquisar a cobrança de pedágio na França ${ }^{27}$. Em 4 de agosto de 1789, cerca de um século após a abolição dos privilégios feudais, o pedágio desaparece no país como método, de direito e de fato, de cobertura de custos de manutenção das estradas e dos canais. Por razões diversas, dentre as quais certamente o desenvolvimento das ferrovias, o instituto cessa em todo o ocidente a partir da primeira metade do século $\mathrm{XIX}^{28}$.

O desenvolvimento do setor automobilístico na segunda metade do século XIX volta a acenar para a construção de rodovias mediante cobranças pedagiais ${ }^{29}$. Segundo Aliomar Baleeiro, pouco antes da segunda Guerra Mundial, o pedágio estava fadado à reabilitação. E, de fato, com a construção da estrada Milano-Laghi, a Itália viu-se dotada de várias rodovias financiadas sob o regime de concessão, mediante cobrança de pedágio ${ }^{30}$.

No início dos anos 50, a França empreendeu um amplo programa ambiental de construção de auto-estradas para recuperar seu atraso em relação à Alemanha e aos países do Norte. Em 1952, é encaminhado um projeto de lei que prevê, ainda em casos excepcionais, a construção e a exploração de estradas pedagiadas sob o regime de concessão para a coletividade pública $^{31}$. Bem mais recentemente, a Lei n. 55.435/1995 autorizou a cobrança nas modernas autoroutes $^{32}$.

O escorço histórico acima delimitado permite entender o pedágio como uma restrição legítima à livre circulação de pessoas e bens, traduzida na exigência de pagamento pela passagem ou utilização de determinada via. Contrapõe-se, nesse sentido, à exploração do direito de trânsito sem o implemento de qualquer contrapartida.

\subsection{O PEDÁGIO NO DIREITO POSITIVO BRASILEIRO}

\footnotetext{
26 SAVARIS. José Antônio. Op. cit., p. 207.

${ }^{27} \mathrm{Na}$ época foram identificados mais de 5.688 pedágios de todas as ordens.

28 SAVARIS. José Antônio. Op. cit., p. 210.

${ }^{29}$ Ibidem.

30 BALEEIRO, Aliomar. Direito Tributário Brasileiro. 10 ed. Rio de Janeiro: Forense, 2012. P. 333

${ }^{31}$ DERYCKE, Pierre-Henri. Le Peage Urbain. Historie, analyse, politiques. In: SAVARIS, José Antônio. Op. cit., p. 211.

32 MEIRELLES, Hely Lopes. Pedágio: Condições para sua cobrança. In: Revista dos Tribunais, v. 430, 1971. P.35.
} 
A primeira via de rodagem do Brasil - a estrada "União e Indústria" - , foi concedida por força de decreto do governo imperial em $1852^{33}$. Ainda em 1848, a Lei 451 da província de Minas Gerais, já havia autorizado a contratação de investidor privado para a construção e exploração da ponte sobre o rio São Francisco. Oportuna a transcrição do artigo $4^{\circ}$ do diploma normativo, que definia a importância que poderia ser exigida dos usuários:

Art. $4^{\circ}$. Aos emprezarios fica concedido o privilegio de arrecadar na sobredita ponte pelo espaço de 40 anos as taxas seguintes: \&1 - de cada pessoa a pé, vinte réis; \& 2 - de cada pessoa a cavalo, ou por cada animal carregado, cento e sessenta réis; \& 3 - de cada animal vacum, cavallar ou muar, tocados, cento e vinte réis; \& 4 - de cada um carro, comprehendendo os animais que o tirarem até o numero de dez, oitocentos réis ${ }^{34}$.

Observa-se que a cobrança do pedágio dependia de autorização legislativa, inclusive quanto à definição de sua regra matriz. A lei indicava como sujeitos ativos o empresário e, como sujeitos passivos, as pessoas a pé, acompanhadas de animais ou em carros. O critério material configurava-se pela travessia da ponte, passível da incidência de tarifas de até oitocentos réis.

Quase um século depois, em 1946, a Constituição passou a contemplar a possibilidade de pedágio, dispondo que:

Art. 27. È vedado à União, aos Estados, ao distrito Federal ao aos Municípios estabelecer limitações ao trafego de pessoas de qualquer natureza por meio de tributos interestaduais ou intermunicipais, ressalvada a cobrança de taxas, inclusive pedágio, destinadas exclusivamente à indenização das despesas de construção, conservação e melhoramento das estradas.

No ano seguinte, o estado de São Paulo instituiu a taxa de rodágio, destinada exclusivamente à indenização de despesas da construção, conservação e melhoramento de Rodovias estaduais. Em 1950, o mesmo ente federado promulgou a Lei n. 784, criando a taxa de pedágio e autorizando a cobrança pelo trânsito em estradas pavimentadas. Na sequência, a Lei 2.481/53 dispôs que a taxa seria cobrada em todas as estradas pavimentadas a concreto, asfalto ou paralelepípedos.

Por meio da Lei Estadual n. 1.260/51, o Poder Executivo paulista foi autorizado a cobrar taxa de pedágio dos usuários da Via Anhanguera, nos trechos São Paulo-Jundiaí e JundiaíCampinas. Um detalhe importantíssimo: o pedágio seria cobrado nos termos da tabela anexa à referida lei e os valores seriam arrecadados pelo Departamento de Estradas e Rodagens.

\footnotetext{
${ }^{33}$ VASQUEZ. Pedro Karp. Album da estradaa da União e Indústria. Rio de Janeiro: Quadratim G, 1998. P. 23.

${ }^{34}$ MACHADO, Kal. Op. cit., p. 80.
} 
Até o final de 1960, o pedágio já era cobrado em outros Estados como Bahia (estrada Itabuna-Ilhéus) e Rio Grande do Sul (estrada Porto Alegre-São Leopoldo). Em 1967, a Constituição continuou a prever a cobrança de pedágio nos seguintes termos:

Art. 20. É vedado a União, aos Estados, ao Distrito Federal e aos Municípios: II estabelecer limitação ao tráfego, no território nacional, de pessoas ou mercadorias por meio de tributos interestaduais e intermunicipais, exceto ao pedágio para atender ao custo de vias de transporte.

\title{
Segundo publicação do Banco Interamericano de Desenvolvimento (BIRD):
}

\begin{abstract}
Os pedágios rodoviários no Brasil tiveram três fases distintas. Antes da Constituição de 1988, eram exigidos desde 1969, nas rodovias federais de pista dupla, inclusive na porte Rio-Niteroi e, desde 1947, nas auto-estradas de São Paulo. Nesta fase, estes pedágios eram operados pelos próprios governos e a maioria era deficitária. A segunda fase se refere à desativação dos pedágios federais, logo após a promulgação da Constituição de 1988, com a instituição do selo pedágio na área federal, na tentativa frustrada de generalizar a cobrança de pedágio. O selo pedágio foi extinto em 1990 e a antiga forma de cobrança de pedágio não foi restabelecida. A terceira e atual fase é caracterizada pela intensificação do pedágio, com adoção do regime de concessões à iniciativa privada, a partir de 1996, por meio da lei 9.277, que permitiu a delegação de rodovias federais a Estados e Municípios, mediante convênio com a União e implantação de novos pedágios por concessões privadas 35 .
\end{abstract}

A Constituição Federal de 1988 volta a contemplar expressamente a possibilidade de cobrança do pedágio nas vias conservadas pelo Poder Público, em seu art. 150, $\mathrm{V}^{36}$. Através de uma simples comparação da atual Lei Superior com os textos constitucional anteriores, é possível identificar que a incidência do pedágio, a partir de 1988, não tem a mesma fundamentação jurídica verificada em 1946 e 1967, onde o produto da sua arrecadação era destinado exclusivamente à indenização das despesas de construção, conservação e melhoramento de estradas. Atualmente, a cobrança redunda da necessidade de manutenção da via pública pelo Poder Público ${ }^{37}$.

\footnotetext{
35 FIRMINO, Antônio Carlos; WRIGTH, Charles Leslie. Financiamento do Setor de Transportes do Brasil. Washington, DC. Banco Interamericano de Desenvolvimento - BIRD. In: SAVARIS, José Antônio. Op. cit., p. 215 36 “Art. 150. Sem prejuízo de outras garantias asseguradas ao contribuinte, é vedado à União, aos Estados, ao Distrito Federal e aos Municípios: V - estabelecer limitações ao tráfego de pessoas ou bens, por meio de tributos interestaduais ou intermunicipais, ressalvada a cobrança de pedágio pela utilização de vias conservadas pelo Poder Público".

37 Assim, pode-se afirmar que a cobrança de pedágio nos termos da Constituição Federal de 1988 pode servir para realizar outros valores que não especificamente o desenvolvimento das vias rodoviárias. Como o pedágio constitui limitação à liberdade de circulação, direito constitucional fundamental, sua instituição, pela lei restritiva deverá buscar a promoção de outros valores de dignidade constitucional, como a promoção da erradicação da pobreza, a busca por um ambiente ecologicamente equilibrado e até mesmo propiciar o uso racional do meio de transporte. Contudo por não ser objeto do presente estudo os breves apontamentos ficam consignados para reflexão do leitor.
} 


\subsection{CONCLUSÕES ACERCA DA NATUREZA JURÍDICA DO PEDÁGIO}

O conceito de pedágio está inevitavelmente ligado ao dever de pagamento pela passagem por determinada via. Reconhecendo no direito de passagem a essência do pedágio, Bernardo Ribeiro de Moraes registra que, na Idade Média "bastava a simples passagem pelos caminhos ou áreas predeterminadas, seja a pé (pedágio), a cavalo, através de barco (barcagem) ou de veículo (rodágio), para ser devido o pedágio" 38 .

Etimologicamente, pedágio significa, do latim, "o direito de pôr o pé" ou "onde se põe o pé”39. Daí a preferência de Aliomar Baleeiro pelo termo "rodágio" para traduzir a imposição pela circulação em vias públicas mediante veículos ${ }^{40}$. Sacha Calmon refere que o pedágio, historicamente, o pagamento pelo uso estradas - o preço que se paga para passar ${ }^{41}$. Para Hector Villegas, o termo refere-se à prestação pecuniária exigida por circular por uma via de comunicação terrestre ou hidrográfica (caminho, ponte, autopista, túnel). ${ }^{42}$

No conceito de Celso Antônio Bandeira de Mello, inclui-se mesmo, a finalidade do pedágio, que compreende, a seu ver:

A designação atribuída a uma cobrança passível de ser exigida dos usuários de via pública, a fim de acobertar despesas na construção, remunerar o trabalho aí implicados ou relativos a sua permanente conservação, bem como serviços complementares disponibilizados a quem deles se utilize ${ }^{43}$.

Já para Pinto Ferreira, o pedágio pode ser definido como "a importância em dinheiro que a União, o Estado, ou o Município cobram dos particulares pela utilização de estradas públicas, para atender exclusivamente a indenizações de despesas com a sua construção e melhoramento" 44 .

Se considerarmos que a construção, manutenção e conservação das vias públicas, estradas, vias de acesso, rodovias e ruas são de competência do Poder Público respectivo União para as estradas federais, Estados para as estradas estaduais e Municípios paras as ruas municipais - podemos concluir que esta atividade constitui típico serviço público. E, dessa

\footnotetext{
38 MORAES, Bernardo Ribeiro. Compêndio de Direito Tributário. 5 ed. Rio de Janeiro, Forense: 1995. P. 337.

${ }^{39}$ MEIRELLES, Hely Lopes. Op. cit., p. 34.

${ }^{40}$ BALEEIRO. Aliomar. Loc. cit.

${ }^{41}$ COELHO. Sacha Calmon Navarro. Curso de Direito Tributário Brasileiro. 6 ed. Rio de Janeiro: Forense, 2007. P. 427.

42 VILLEGAS. Hector Belisário. Curso de Finanzas, Derecho Financeiro y tributário. 8 ed. Buenos Aires: Astrea, 2003. P. 200.

${ }^{43}$ MELLO. Celso Antônio Bandeira de. Pedágio - Decisões e Pareceres Jurídicos sobre pedágio. São Paulo: ABCR, 2002. P. 11.

${ }^{44}$ FERREIRA. Pinto. Comentários à Constituição Brasileira. V. 5. São Paulo: Saraiva, 1992. P. 321.
} 
forma, pode ser objeto de imposição de taxa, visto que especifico, divisível e efetivamente gozado pelo contribuinte.

No caso da utilização das estradas, dúvidas não restam acerca da divisibilidade e especificidade do serviço, não havendo qualquer dificuldade em relação à individualização do uso - o que pode ser contabilizado em razão, por exemplo, de cada evento de utilização, por períodos de uso $^{45}$ ou ainda pelas distâncias percorridas ${ }^{46}$. A divisibilidade do serviço refere-se, enfim, a um "desdobramento da especificidade do serviço, se o serviço é específico também se poderá identificar os sujeitos passivos do serviço" ${ }^{47}$.

Conclui-se, por conseguinte, que o pedágio constitui a contrapartida pela fruição de um serviço público específico e divisível. Logo, sua efetiva fruição pelo usuário pode ensejar a cobrança de taxa, a qual foi especialmente denominada como "pedágio" 48 .

Para alguns autores, como Hely Lopes Meirelles, o pedágio não constitui espécie de taxa, possuindo natureza jurídica de preço público. Não foi a tese que prevaleceu na Constituição Federal, contudo. Tendo a Lei Maior de 1988 excluído expressamente o instituto das limitações ao poder de tributar, constituiu inegável indício de que o pedágio seria, ele próprio um tributo - de outro modo, a exclusão teria sido escancaradamente redundante.

O artigo 175 da Constituição Federal de 1988 estabelece que incumbe ao Poder Público a prestação, diretamente ou por concessão, de serviços públicos. Os serviços públicos ali referidos são indiscutivelmente os mesmos serviços referidos no artigo 145, II, da Lei Superior que, por sua vez, constituem o suporte fático para a instituição da taxa (prestação de serviço específico e divisível, efetivamente prestados ao contribuinte).

Assim, caso o Estado pretenda obter contrapartida pela prestação de serviço público individualizável, somente poderá fazê-lo por meio do implemento de taxa - caso contrário

\footnotetext{
${ }^{45}$ Em recente visita a Eslovênia, este autor pode verificar que, para utilização das estradas conservadas pelo Poder Público, é exigido pedágio semanal. Paga-se um valor para utilizar as estradas pelo período de uma semana. O controle é feito por foto sensores que verificam a validade do selo obtido no momento do pagamento do pedágio.

${ }^{46}$ No norte da Itália, o pedágio é cobrado em razão da quantidade de kilometros percorrido nas estradas conservadas pelo Poder Público.

${ }^{47}$ PEREIRA FILHO, Luiz Alberto. As Taxas e os Preços no Ordenamento Jurídico Brasileiro. In: DE SANTI, Eurico Marco (coord.). Curso de especialização em Direito Tributário: Estudos Analíticos em Homenagem a Paulo de Barros Carvalho. 1 ed. 2007. P. 66.

48 Os escorços históricos dão sentido ao nome utilizado pelo legislador constituinte de 1988. Exação sempre relacionada ao direito de passagem.
} 
deverá prestá-lo de forma gratuita ${ }^{49}$. Não havendo acordo de vontade entre prestador e usuário, reitera-se, não há que se falar em cobrança de "preço" de qualquer tipo:

A eventual contraprestação pecuniária que o usuário do serviço for obrigado a desembolsar não pode ter natureza de preço, pois esta é figura nitidamente decorrente de relações de disponibilidade e liberdade estipulativa, o que não ocorre no serviço público que é por determinação constitucional, uma das entidades fora do mercado ${ }^{50}$.

É preciso lembrar que a concessão do serviço público, feita a terceiro pelo Poder Público, não pode alterar seu regime jurídico. Assim, se a administração prestar o serviço remunerado por meio de taxa, o concessionário da atividade somente poderá realizar cobrança pela sua prestação por meio desta espécie tributária. Não pode o Estado transferir, na concessão, prerrogativa que não detém.

A concessão não pode ser vista como forma de burlar os direitos e garantias constitucionais assegurados ao contribuinte, o que inevitavelmente ocorreria caso a remuneração pelo serviço perdesse a sua natureza de tributo. Dessa forma, caso a administração pretenda transferir ao concessionário a capacidade tributária ativa que possui, deverá fazê-lo de forma a preservar sua competência tributária, a qual é imprescritível e irrenunciável:

O sujeito passivo deverá pagar a taxa porque o ente competente para tributar previu, em lei, que deverá ser exigido o tributo daquele que tiver o serviço público, específico e divisível colocado a sua disposição, ou daquele que o tiver utilizado, independentemente de quem tiver prestado, se a Administração Pública, ou o terceiro $^{51}$.

Inegável, portanto, que a relação travada entre a concessionária e o usuário do serviço público assume natureza tributária. Terá por objeto o pagamento de uma tarifa - espécie de taxa, reitera-se -, a qual terá seus critérios material, espacial e temporal estipulados unicamente por meio de lei. De fato, jamais será prerrogativa do concessionário fixar, por exemplo, o valor ou o fato gerador da taxa:

Em primeiro lugar, deve ter-se em vista que a competência para a fixação da tarifa é do Estado, sendo inviável sua delegação a particular. Portanto o artigo $9^{\circ}$ não prevê que a tarifa seja fixada pelo particular, por meio da proposta vencedora. Dispõe, isto sim, que será ela estabelecida tendo em vista o valor constante da proposta vencedora $^{52}$.

\footnotetext{
${ }^{49}$ Um exemplo clássico de serviço público gratuito é a educação básica dos 04 aos 17 anos por expressa imposição constitucional, Artigo 208, inciso I.

50 GRECO, Marco Aurélio; SOUZA, Hamilton Dias de. Natureza Jurídica das custas judiciais. São Paulo: Resenha Tributária, 1992. P.54.

51 PEREIRA FILHO. Luiz Alberto. Op. cit., p. 66.

${ }^{52}$ JUSTEN FILHO, Marçal. Op. cit., p. 366.
} 
Ao adquirir a concessão de dado serviço público, a parte concessionária passa a integrar a regra matriz tributária na condição de sujeito ativo da exação. Trata-se, neste tocante, de típico caso de parafiscalidade. O usuário do serviço, obviamente, permanecerá na condição de sujeito passivo da relação fiscal. Não há que se falar, neste caso, em qualquer relação de preço público entre concedente e concessionária ${ }^{53}$ - o vínculo tributário existirá somente entre o concedente (por meio da concessionária) e o usuário contribuinte.

A lei que permitir a concessão deverá também fixar a regra matriz da taxa a ser cobrada do usuário. A esta circunstância atribui-se o nome de "concessão de tarifa", visto que previamente estipulada a taxa em tabela anexa ao edital de concessão. Nesse sentido, é válida a transcrição do artigo $2^{\circ}$ da lei 9.074/95:

Art. $2^{\circ}$ - É vedado à União, aos Estados, ao Distrito Federal e aos Municípios executarem obras e serviços públicos por meio de concessão e permissão de serviço público, sem lei que lhes autorize e fixe os termos, dispensada a lei autorizativa nos casos de saneamento básico e limpeza urbana e nos já referidos na Constituição Federal, nas Constituições Estaduais e nas Leis Orgânicas do Distrito Federal e Municípios, observado, em qualquer caso, os termos da Lei nº 8.987, de 1995.

${ }^{53}$ Evidentemente que caso o concessionário pague um preço ao poder concedente, ou deste receba um preço para subsidiar a prestação do serviço público concedido, esse preço possui a natureza de preço público. 


\section{CONCLUSÃO}

As premissas fixadas ao longo do presente estudo e investigação constitucional do sistema tributário e de suas limitações, bem como a análise legislativa e doutrinária aqui realizados, permitem concluir que o pedágio possui natureza jurídica de taxa. Encontra-se sujeito, portanto, sujeito a todas a regras e princípios aplicáveis a esta espécie tributária.

Conforme definimos, as taxas são tributos aptos a remunerar a prestação de serviços públicos específicos e divisíveis. A manutenção das rodovias, por sua vez, constitui atribuição primordial do Poder Público e, como tal, pode ser caracterizada como prestação pública direcionada ao administrado. Trata-se, assim, de serviço público, cuja utilização individualizada pelo usuário pode ser materialmente mensurada.

Verificou-se, ainda, que a concessão do serviço público não transmuda sua natureza e, muito menos, seu regime jurídico. Dessa forma, a relação existente entre prestador do serviço público e usuário deve respeitar os direitos e garantias constitucionalmente assegurados ao contribuinte. Eventual remuneração imposta ao usuário como contrapartida pela prestação de pedágio deve, portanto, assumir natureza de tarifa - espécie tributária do gênero taxa. 


\section{REFERÊNCIAS}

ATALIBA. Geraldo. Hipótese de Incidência Tributária. 5 ed. São Paulo: Malheiros, 2011.

BALEEIRO, Aliomar. Direito Tributário Brasileiro. 10 ed. Rio de Janeiro: Forense, 2012.,

CARVALHO, Paulo de Barros. Curso de Direito Tributário. São Paulo: Saraiva, 2003.

Direito Tributário, linguagem e método. 3 ed. São Paulo: Noeses, 2009.

COELHO. Sacha Calmon Navarro. Curso de Direito Tributário Brasileiro. 6 ed. Rio de Janeiro: Forense, 2007.

COSTA, Ramon Valdes. Curso de Derecho Tributário. 1 ed. v. 1. Montevidedo: Impressora Uruguaya Colombino: 1970.

DERYCKE, Pierre-Henri. Le Peage Urbain. Historie, analyse, politiques. In: SAVARIS, José Antônio. Pedágio: Conceitos e Trajetória Histórica. In: Caderno da Escola de Direito e Relações Internacionais, p. 200-24, 2008.

FERREIRA. Pinto. Comentários à Constituição Brasileira. V. 5. São Paulo: Saraiva, 1992.

FOURQUIN, Guy. Senhorio e Feudalidade na Idade Média.Lisboa. Lisboa: Edições 70, 1987. GRECO, Marco Aurélio; SOUZA, Hamilton Dias de. Natureza Jurídica das custas judiciais. São Paulo: Resenha Tributária, 1992.

JUSTEN FILHO, Marçal. Teoria Geral das Concessões de Serviço Público. 1 ed. São Paulo: Dialética, 2003.

MACHADO, Kal. Concessões de Rodovias. Mito e realidade. São Paulo: Premio 2002.

MEIRELLES, Hely Lopes. Pedágio: Condições para sua cobrança. In: Revista dos Tribunais, v. 430, 1971.

MELLO. Celso Antônio Bandeira de. Pedágio - Decisões e Pareceres Jurídicos sobre pedágio. São Paulo: ABCR, 2002.

MORAES, Bernardo Ribeiro de. Compêndio de Direito Tributário. 5 ed. Rio de Janeiro, Forense: 1995.

Doutrina e Prática das Taxas. 2 ed. São Paulo: Quartier Latin. $2^{a}$ edição. 2007.

PEREIRA FILHO, Luiz Alberto. As Taxas e os Preços no Ordenamento Jurídico Brasileiro. In: DE SANTI, Eurico Marco (coord.). Curso de especialização em Direito Tributário: Estudos Analíticos em Homenagem a Paulo de Barros Carvalho. 1 ed. 2007.

SAVARIS, José Antônio. Pedágio: Conceitos e Trajetória Histórica. In: Caderno da Escola de Direito e Relações Internacionais, p. 200-24, 2008. 
VASQUEZ. Pedro Karp. Album da estradaa da União e Indústria. Rio de Janeiro: Quadratim G, 1998.

VILLEGAS. Hector Belisário. Curso de Finanzas, Derecho Financeiro y tributário. 8 ed. Buenos Aires: Astrea, 2003. 